\title{
El debate sobre las necesidades, y la cuestión de la "naturaleza humana" (Teniendo como trasfondo la interrogante sobre la posibilidad de una nueva civilización)
}

\author{
Luis Razeto M.*
}

\begin{abstract}
Resumen: En el artículo se aborda la cuestión filosófica de la "naturaleza humana”, de cuya respuesta depende la posibilidad de cambios económicos, políticos y sociales, más o menos profundos y extendidos. En tal contexto, se parte examinando el comportamiento del consumidor moderno, cuyas necesidades, aspiraciones y deseos y el modo de satisfacerlos actualmente, parecieran constituir un obstáculo insalvable para generar tales procesos de cambio. Si el modo de ser del consumidor moderno fuese expresión cabal y coherente de la naturaleza humana, sería utópico pretender un perfeccionamiento ético que viabilice una nueva y superior civilización. Para responder la cuestión, se efectúa un análisis de las necesidades humanas y de las distintas teorías que las conceptualizan en términos tales que justifican las instituciones económicas que predominan en las sociedades modernas. Una nueva concepción de las necesidades humanas, fundada en una reformulación filosófica de la "naturaleza humana" esencial, conducen a una nueva forma de concebir los procesos de desarrollo humano, tanto a nivel personal como social y civilizatorio.

Palabras clave: Desarrollo humano, desarrollo personal, naturaleza humana, necesidades, espiritualidad, identidad, Economía Solidaria, consumo, civilización.
\end{abstract}

\section{The debate about the needs, and the issue of "human nature" \\ (Having as a backdrop the question about the possibility of a new civilization)}

\begin{abstract}
This paper addresses the philosophical question of human nature, whose answer depends on the possibility of changing economic, political and social rights, more or less profound and widespread. In this context, we will examine the behavior of the modern consumer, whose needs, aspirations and desires and how to meet them now, seem to constitute an insurmountable obstacle for generating such processes of change. If the mode of being of the modern consumer would be fair and consistent expression of human nature, it would be unrealistic to pretend an ethical refinement that could make viable a new and higher civilization. To answer the question, an analysis of human needs and the various theories that conceptualize it in such terms to justify the economic institutions that dominate modern societies, is undertaken. A new conception of human needs, based on a philosophical rethinking of "human nature" will lead to a new way of conceiving
\end{abstract}

*Universidad Bolivariana, Santiago, Chile. Email: Irazeto@ubolivariana.cl 
the processes of human development, both at personal as well as at social and civilizatory level.

Key words: Human development, personal development, human nature, needs, spirituality, identity, Solidarity Economy, consumer, civilization.

Recibido: 08.06.2009

Aceptado: 08.07.2009

$* * *$

\section{El “consumidor moderno” como obstáculo (aparentemente) insalvable para un proyecto de transformación social y de creación de una nueva civilización}

A lo largo de la época moderna se han formulado e intentado numerosos proyectos de cambio social, económico y político tendientes a crear una sociedad más justa, o una civilización más humana. Tales intentos han alcanzado ciertos niveles de desarrollo interesantes, son preciosos en cuanto testimonio de la posibilidad de otra economía y de otra política, éticamente superiores a la capitalista y estatista. Pero no han podido hasta ahora convencer de que sean también más eficientes desde el punto de vista de la satisfacción de las necesidades humanas individuales y colectivas, o que sean suficientemente realistas en cuanto a su viabilidad y permanencia en el tiempo. De hecho tales proyectos no han logrado prevalecer ni consolidarse a nivel suficientemente general como para convencer de sus reales ventajas y conveniencia para todos.

Una de las principales críticas que se hacen a estos proyectos de cambio y creación de nuevas formas y estructuras sociales es que no tienen en cuenta a los seres humanos tales como son, con sus complejas necesidades, aspiraciones y deseos, por lo cual serían en definitiva proyectos utópicos, que están destinados a fracasar por no basarse en una comprensión realista de la "naturaleza humana”.

Y en efecto, es esencial la cuestión de la "naturaleza humana” cuando se trata de proponer la creación de una nueva economía, de una nueva organización política y de una superior civilización. Cualquier proyecto de sociedad que suponga la participación libre de las personas en su construcción, debe ser realista respecto a los comportamientos que se puedan esperar de los individuos y grupos en lo que se refiere a su disposición al trabajo, las opciones de consumo, el deseo de poseer y acumular, la voluntad de participación en organizaciones y comunidades, etc. En síntesis, se requiere una correcta comprensión de las necesidades, aspiraciones y deseos de las personas, en correspondencia con la que sería la "naturaleza humana”.

Es evidente que toda concepción económica y política suficientemente coherente debe fundarse en alguna filosofía o antropología, que incluya un particular modo de entender las necesidades humanas. Así, la eco- 
nomía y la política liberales se fundamentan en una manera positivista de comprender a los seres humanos y sus necesidades. Según dicha concepción, no existiría en realidad una esencia o naturaleza humana común a todos los hombres, sino solamente individuos que son como se comportan y muestran empíricamente, con toda su diversidad y diferenciación, cada uno provisto de aquellos intereses, necesidades, deseos y características que ponen de manifiesto en sus actuaciones y en sus mutuas relaciones. La sociedad como tal tampoco existiría como un todo orgánico, siendo no otra cosa que el conjunto de los individuos interrelacionados e interactuando concretamente en territorios determinados, efectuando unos con otros intercambios y contratos que configuran los mercados, y dando lugar a un orden político en base a relaciones de fuerza y a acuerdos, pactos y convenciones sociales y jurídicas.

Según esta concepción, las necesidades son individuales y se manifiestan directamente en aquello que los individuos demandan y compran en el mercado. Cada individuo tiene necesidades distintas, que responden a su edad, a sus características personales, a sus gustos, a su grado de desarrollo, a sus condiciones propias corporales, a su intelecto, a sus niveles de ingreso. Todos los individuos son distintos, y aunque compartan algunas necesidades (todos tenemos necesidad de comer), las necesidades se experimentan individualmente y será cada uno quien determina qué comer, cuándo comer, donde comer, etc. Las necesidades deben ser expresadas por los individuos, partiendo de la base que somos todos distintos y que hacemos opciones libres. Por ello, no corresponde que nadie nos diga qué necesitamos satisfacer, pues cada uno lo sabe y lo puede expresar.

Además, las necesidades serían recurrentes, es decir, se satisfacen cada vez, pero vuelven al poco tiempo a presentarse insatisfechas, porque se las concibe como carencias o vacíos que están permanentemente llenándose, o sea, satisfaciéndose, y volviendo luego a vaciarse, y por lo tanto estarían constantemente demandando los bienes y servicios que los llenan o completan en el momento, pero que luego -cuando el bien o servicio termina de prestar su utilidad-, vuelven a presentarse insatisfechas.

Junto con ser recurrentes, se piensa que las necesidades son crecientes. Los seres humanos, una vez que satisfacemos ciertas necesidades, queremos siempre satisfacer otras, nuevas, más amplias y más sofisticadas necesidades. Y estamos siempre de alguna manera en un grado de insatisfacción. Los seres humanos satisfacen en determinado momento unas necesidades, y después quieren más. No somos como los animales que se mantienen en un estado estacionario de necesidades, sino que vamos ampliando, multiplicando, diversificando, sofisticando nuestras necesidades. Puede decirse en tal sentido, que los seres humanos seríamos insaciables.

Las necesidades -así entendidas- se satisfacen con productos y servicios. Las necesidades son esas carencias o vacíos que encuentran apagamiento o satisfacción a través de bienes y servicios que los llenan cuando son consumidos por cada individuo. Por lo tanto, hay una suerte de corres- 
pondencia biunívoca entre necesidades y productos y servicios. A cada necesidad corresponde un producto y servicio o una gama de productos y servicios entre los cuales cada individuo puede optar. Y a cada producto y servicio corresponde una necesidad, puesto que cada producto o servicio está hecho y predispuesto en función de satisfacer necesidades determinadas. Como las necesidades van expandiéndose, multiplicándose y diversificándose, también la economía va multiplicando y diversificando los productos y servicios que ofrece. Y están surgiendo constantemente en la economía más bienes y más servicios para satisfacer más necesidades y más deseos que aparecen en las personas. Los vacíos, las carencias que experimentan los individuos en este proceso, cada vez que se llenan vuelven a presentarse luego como vacíos más grandes, por lo que se requieren recurrentemente más bienes y servicios para llenarlos. Seríamos, pues, insaciables.

Otra muy distinta concepción de las necesidades que es también parte de la civilización y economía modernas, y que también se formula en dependencia del cientismo positivista -aunque se presenta como opuesta o diametralmente distinta a la concepción liberal -, es la que corresponde al enfoque de la planificación centralizada y de la organización económica estatista. La concepción del hombre subyacente es aquella postulada inicialmente por Ludwig Feuerbach y desarrollada por Marx y Engels en el denominado materialismo histórico, según la cual la "naturaleza humana" no tiene nada que se parezca a una esencia constitutiva presente en cada persona, sino que se identifica directamente con la especie humana, o con la sociedad entendida como especie natural. La "naturaleza humana” sería nada más que el conjunto de las relaciones sociales, históricamente determinadas.

Esta concepción del hombre y de sus necesidades también las concibe como carencias, como vacíos recurrentes que se satisfacen con productos. Pero se diferencia de la anteriormente expuesta, en que hace una neta distinción entre las que serían las verdaderas necesidades humanas -aquellas propias de la especie-, y los que serían solamente deseos, aspiraciones y caprichos individuales. Las verdaderas necesidades serían claramente identificables y prácticamente iguales para todos. Son necesidades comunes a todos los hombres: todos tenemos más o menos las mismas necesidades de alimentarnos, vestirnos, habitar una vivienda, adquirir conocimientos indispensables, disponer de cuidados de salud, etc. Por lo tanto cada sociedad puede definir sus necesidades como colectivo; es la sociedad la que puede determinar las necesidades que en cada momento tiene y debe satisfacer. No le corresponde a cada individuo determinar sus necesidades, porque cada individuo es parte de una colectividad, y cuando se separa de la colectividad y actúa como individuo, expresa sus caprichos y deseos individualistas que lo ponen en contra del bien colectivo, separándolo de la especie humana o sociedad.

Según este enfoque, las necesidades son pocas, son determinables claramente, y son perfectamente jerarquizables, desde las necesidades más 
básicas a las más sofisticadas, de tal manera que se puede planificar su satisfacción a través de la acción del Estado.

Las necesidades desde esa óptica no son relevadas o puestas de manifiesto en el mercado por cada individuo, sino que son técnica y autoritariamente definidas, por acción de la autoridad, para cada momento histórico. Es la colectividad la que va determinando las necesidades que en la dinámica expansiva de la economía pueden o no ir siendo satisfechas. Pero como la sociedad se encuentra dividida en clases sociales, la especie humana es representada en cada época histórica por la clase progresista, y hasta que no se cumpla la plena integración de la especie, corresponderá al Estado (controlado por la clase progresiva) representar a la colectividad. Por lo tanto, hay que planificar la economía, regularla estrictamente, y hay que reducir los espacios de libertad en que los individuos expresen sus necesidades, porque si cada individuo persistiera en expresar libremente sus demandas, no hay planificación que se pueda realizar de manera coherente. Convendrá, pues, aplacar las necesidades individuales, regularlas estableciendo nítidamente aquellas que serían legítimas o aceptables, reprimirlas si es necesario e impedir que se manifiesten individualmente, puesto que los seres humanos deben expresarlas socialmente y de manera racional, en el marco de un plan o programa coherente de satisfacción de necesidades. En una versión menos radical y actualmente más aceptada, corresponde a la mayoría social expresada a través de los mecanismos de representación democrática controlar el Estado y determinar las necesidades comunes que el Estado debe garantizar.

Hay una relativamente estrecha correspondencia entre estas dos concepciones del hombre y de las necesidades, y lo que postulan los principales proyectos políticos que se confrontan en la sociedad moderna. Pero lo que ha tendido a predominar es cierta posición intermedia, o una mezcla de ambas. Por un lado hay un reconocimiento creciente de que los individuos tienen necesidades legítimas, que pueden expresar con libertad y buscar su satisfacción con los medios que cada uno pueda lograr. Por lo tanto, existe una legitimación del mercado como instrumento de acceso a los bienes y servicios para satisfacer las necesidades y como lugar donde éstas pueden manifestarse. Hoy día nadie discutiría que las personas pueden comprar con su dinero lo que se les ofrezca en el mercado y demandar otros bienes -si no les son ofrecidos- a alguien que se los pueda elaborar.

Pero al mismo tiempo hay consenso, cierto acuerdo social, de que existe un nivel básico de necesidades que es común a todas las personas, que todos tenemos que satisfacer, y que no queda subordinado a la dinámica del mercado. Entonces se reconoce la legitimidad de que un orden de necesidades sea regulado, y sea ofrecida su satisfacción por el Estado mediante una acción planificada, con leyes que establecen mínimos de bienestar para todos, que establecen niveles de acceso a ciertos bienes y servicios que es indispensable satisfacer. La satisfacción de estas necesidades generales es concebida como derechos que los ciudadanos pueden exigir al Estado. 
Ahora, este reconocimiento de ambas lógicas como legítimas da lugar a una estructura de las necesidades, y a un tipo de consumidor -lo llamaremos el consumidor moderno- muy complicado, que genera un problema económico tendencialmente insoluble, y que como lo iremos comprendiendo cada vez mejor, es lo que origina la gran crisis orgánica que afecta a la actual civilización moderna.

En efecto, desde ambas racionalidades (la del mercado libre y la del Estado proveedor), las necesidades están creciendo, multiplicándose y diversificándose, y en consecuencia la economía está fuertemente presionada a crecer, a multiplicar su oferta de bienes y servicios para satisfacer tanto las necesidades colectivas como las individuales, o sea, tanto las necesidades expresadas ante el Estado como demanda común para todos, como aquellas que se expresan ante el mercado con libre acceso individual. Desde ambas perspectivas, desde ambas lógicas, se está viviendo un elevamiento del umbral de lo que se demanda, y del nivel al cual se aspira.

Por un lado está la lógica del mercado, que es fundamentalmente una lógica de individuación, una lógica de diferenciación, donde cada cual trata de diferenciarse, de prestigiarse, de competir con el otro, de tener por lo tanto más acceso a bienes y servicios. Entonces se produce una competencia entre los individuos que hace que quienes tienen poder de compra, quienes tienen capacidad de acceso a ciertos bienes en el mercado, demanden productos, bienes y servicios cada vez más sofisticados, cada vez más complejos, más amplios o en cantidades mayores. Pero al mismo tiempo se genera socialmente también un elevamiento consistente y persistente del nivel mínimo considerado socialmente aceptable. De tal manera, que cada vez el Estado es exigido a ofrecerle a sus integrantes niveles crecientes de satisfacción de sus necesidades; mejor alimentación, mejores condiciones de habitabilidad mínima, mejores medios de transporte común para todos, mejores sistemas educativos, mejores servicios de salud, niveles de acceso a la educación cada vez más elevados, etc.

El elevamiento del nivel individual genera un elevamiento del nivel colectivo, por efecto demostración, por efecto de imitación, por efecto de que "bueno, lo que otros tienen por qué no lo podemos tener todos". A su vez, el elevamiento del nivel de lo que es común para todos, genera una presión hacia el mercado para diferenciarse, porque si, por ejemplo, ya todos tuvieran educación universitaria, el mercado generaría las instancias para todos aquellos que quieran ser más que el común, y que por lo tanto presionan por niveles de enseñanza más elevados para sus hijos. Y así en todos los ámbitos de necesidades.

El consumidor moderno, además de ser insaciable, es tremendamente demandante y exigente frente al Estado, pues considera que tiene derecho a que el Estado le provea de todo lo que se necesita para alcanzar el nivel social medio, y además, que tiene derecho a que el mercado le proporcione todo lo que desee y pueda pagar. Y si no lo puede pagar, considera que tiene derecho a que le den el crédito necesario para comprarlo. 
Todo esto da lugar a un proceso de aceleración impresionante de las demandas, tanto individuales como sociales. Es lo que hemos estamos viviendo desde hace años. Y esa expansión y esa explosión de las necesidades y de las demandas hacia ambos sistemas a través de los cuales se busca satisfacción, genera una presión enorme sobre el sistema productivo. Una presión para crecer, es decir, para aumentar el proceso de producción de bienes y servicios junto con la expansión de las necesidades.

Tal como lo hemos descrito, el consumidor moderno -sujeto insaciable cuyas necesidades y deseos están en perpetuo crecimiento, que busca proveerse siempre y cada vez de más objetos y servicios que llenen sus propias carencias recurrentemente insatisfechas, y que en el mercado está en una constante búsqueda de novedades y de accesorios que lo diferencien de los demás con quienes se encuentra siempre en competencia -es un individuo que probablemente nos resulte poco simpático y nada atractivo. Nos resultaría en cambio decididamente desagradable si nos diésemos cuenta de que ese mismo comportamiento que tiene respecto de los bienes y servicios habitualmente lo extiende también respecto de las personas con las que se relaciona e interactúa, en el sentido de que también en ellas busca constantemente la utilidad para sí, esto es, que le sean útiles y contribuyan a la satisfacción de sus propias necesidades, aspiraciones y deseos. Pero de todo esto las personas raramente se dan cuenta, no son conscientes, si bien en los hechos los individuos tienden a desconfiar más que a fiarse de los otros. Y sin embargo, como casi todos deben reconocerse parecidos a dicho consumidor, y por tanto deben aceptar que tienen comportamientos similares, terminan por adaptarse y aceptarse civilmente unos a otros, y a menudo incluso se respetan y parecen quererse (especialmente cuando se encuentran unos al lado de los otros haciendo shopping o hablando de sus compras). Es un hecho, además, que las personas tienden a querer a aquellos que se les parecen, y a discriminar y rechazar (despreciar o envidiar según sea el caso) a los diferentes.

Pero está, además, el otro lado del comportamiento de los consumidores modernos, que los torna en cierto modo amables en cuanto establece entre ellos un terreno común, un compartir objetivos e intereses. Me refiero al hecho de que este mismo consumidor moderno pide y exige al Estado siempre mayores y mejores soluciones que impliquen niveles de creciente bienestar social iguales para todos. Esto lleva a los consumidores -en este caso, a los demandantes de bienes y servicios públicos- a organizarse en función de realizar actividades de presión y reivindicación de derechos frente al Estado. Sin embargo, no necesariamente esto establece un nivel ético superior. En algunos casos puede entenderse así (por ejemplo, cuando personas idealistas solicitan el cumplimiento de los derechos para categorías o grupos sociales desfavorecidas); pero habitualmente los grupos se organizan para exigir beneficios para ellos mismos, y los exigen aún a menudo sabiendo que los recursos limitados que tiene el Estado podrían emplearse de manera socialmente más útil, provechosa o justa, en vez de hacerlo del modo en que el grupo lo exige. Además, a menudo se exigen como derechos, ciertos bienes y servicios que en realidad constituyen privilegios. En 
fin, sucede también que algunas "luchas" por los derechos esconde un componente de envidia social.

Pues bien, cuando este “consumidor moderno" se generaliza y expande por toda la sociedad, difícilmente puede pensarse en un cambio profundo de la sociedad, ni menos en la construcción de una nueva civilización éticamente superior. Entonces, desde el punto de vista teórico en que estamos desarrollando este análisis, lo que interesa es saber si este consumidor moderno y este modo de entender y de vivir las necesidades, corresponda a la "naturaleza humana”, o si se trata más bien de una manera de ser que puede cambiarse y sustituirse por otra, que podamos considerar "más humana”. La cuestión es crucial, porque como hemos visto, no tiene sentido proponer un tipo de economía o un proyecto de nueva civilización que no se base y tenga en cuenta a los seres humanos tales como son.

\section{La estructura de necesidades del "consumidor moderno" como expresión de una "segunda naturaleza”, construida socialmente encima de la verdadera "naturaleza humana" esencial}

Es probable que, puestos ante esta descripción del "consumidor moderno" y ante esta presentación de las necesidades humanas, muchos tienden a pensar que correspondan bien a la "naturaleza humana”. "Así son los seres humanos”, se piensa en primera instancia. Sin embargo, esas mismas personas difícilmente estén dispuestas a aceptar que ellas se comporten de esa manera, o que estén bien representados por esa descripción del consumidor moderno que lo muestra como ávido, individualista, posesivo, exigente, envidioso.

El hecho de que las personas estén más dispuestas a atribuir a los demás este modo de ser y de comportarse y tengan dificultad para reconocerlo como el propio modo de ser, no habla solamente de una diferente medida para juzgar y juzgarse, más estricta para los otros y más complaciente para sí. Además de ello, puede hipotetizarse que cada uno de nosotros, incluso si aceptamos que nos comportemos a menudo del modo indicado, pensamos sin embargo en la intimidad que no somos así, o al menos que no lo hemos sido siempre, o que fuimos diferentes en algunas fases o momentos de la vida, y en todo caso que tenemos la posibilidad de comportarnos diversamente. Pero si ello es así, o bien si estamos al menos dispuestos a aceptar que algunas personas actúen de modo diferente, o si ha habido comportamientos distintos en el pasado histórico, entonces no se puede absolutamente decir que el consumidor moderno sea la única y cabal expresión de la "naturaleza humana”.

Sin embargo, es necesario compatibilizar esto con el hecho de que las personas -de manera muy generalizada- son realmente tal como las hemos descrito (consumidores modernos) y que este comportamiento y modo 
de ser está de hecho profundamente enraizado en los individuos de nuestra sociedad y civilización.

Existe un modo preciso de comprenderlo. Es concebir la "naturaleza humana" como una cierta estructura de base, constituida por algunos elementos esenciales generales y comunes a todas las personas independientemente de la época, la organización social, las condiciones históricas, etc. Una naturaleza "esencial” que, sin embargo, está y permanece abierta a -o que tiene la posibilidad de- adquirir diversas formas más complejas que la puedan en cierto sentido convertir o hacer evolucionar a otra estructura; o mejor, una estructura básica, primaria, sobre la cual se pueden levantar otras estructuras; o bien, como una determinada "naturaleza humana" sobre la cual se pueda establecer una "segunda naturaleza", que a su vez se presente con diferentes alternativas posibles. En este sentido, el modo de ser y de comportarse del consumidor moderno, con su manera de vivir y de satisfacer sus necesidades, no sería la expresión directa de la "naturaleza humana”, sino la manifestación de una "segunda naturaleza”, que se levanta sobre la primera, y que ha sido creada en el curso de la constitución y desarrollo de una civilización y de una economía capitalista, estatista y consumista que la necesita como sistema.

La idea de que sobre la "naturaleza humana” esencial puedan levantarse "segundas naturalezas”, no es nueva. Diferentes autores se han referido a una "segunda naturaleza" humana, pero entienden por ella cosas diferentes. Para algunos se trata de la naturaleza humana consciente, que debe distinguirse de la naturaleza humana biológica. Otros toman el término en sentido histórico, y conciben la "segunda naturaleza" para referirse a tipos humanos que se caracterizan por su pertenencia a una religión o a una ideología política. Algunos piensan en la idea de un "hombre nuevo" como portador de una "segunda naturaleza". Y tal vez en la base de todas estas concepciones esté el antiguo proverbio que dice: "La costumbre es una segunda naturaleza de los hombres”.

Estas distintas ideas sobre la "segunda naturaleza" tienen alguna relación con el concepto que estamos presentando, pero referir el término al consumidor moderno (o más en general, al concepto de "homo oeconomicus" sobre el que se fundamenta la elaboración teórica de la economía capitalista) trae novedades y aporta una mayor profundidad teórica. En particular, la cuestión teóricamente importante para nosotros es comprender cómo pueda concebirse una "segunda naturaleza”, y qué relación tenga con la "naturaleza humana” propiamente tal.

Ante todo, es obvio que la existencia de "segundas naturalezas" supone que la "naturaleza humana" sea tal que permita que sobre ella se levanten esas "segundas naturalezas". Como esto no parece que pueda atribuirse a las demás especies animales, identificaremos en la característica específicamente humana de la conciencia, y más precisamente, en la racionalidad y en la libertad, el fundamento que hace posible la creación de la "segundas naturalezas". Esa conciencia libre, en efecto, hace posible que 
los hombres se disocien respecto a una naturaleza biológica común (propia de la especie), o mejor dicho, que tomen bajo su control la dirección del propio desarrollo y evolución. Es indispensable ser libres para tener la posibilidad de diferenciarse y cambiar, y ser racionales para tomar el control y definir una dirección al cambio, de modo que se pueda desarrollar un cierto modo de ser, o crear "otra estructura” como hemos definido también la "segunda naturaleza".

No es suficiente, sin embargo, la conciencia y la libertad para fundamentar una supuesta "segunda naturaleza". En efecto, la conciencia y la libertad son individuales, esto es, atributos de los individuos que les permiten actuar como tales individuos. En este sentido, la disociación y la autodirección que se imprima al desarrollo propio, pudiera resultar infinitamente diferenciado (para cada individuo libre, un diferente modo de ser). En cambio, estamos hablando de una "segunda naturaleza" que si bien pudiera no entenderse como involucrando a todos los seres humanos, a la especie completa, incluiría y subsumiría a una gran población humana.

Por ello, la "segunda naturaleza" no puede sino ser "social”. Y la socialidad es, en efecto, propia de la "naturaleza humana”, igual como lo son la racionalidad y la libertad a que nos hemos referido. Esto significa que una "segunda naturaleza" no puede crearse sino combinando procesos individuales con procesos sociales, esto es, como un proceso de construcción social que incorpora a muchos individuos asociados, que comparten una cierta racionalidad y una voluntad de integrarse a un proceso de creación colectiva; o bien, que sean integrados a un modo de ser colectivo a través de la coerción y del consenso o conformismo. En todo caso, cuando decimos proceso "social”, decimos más concretamente proceso "económico", "político”, “cultural”, que son las dimensiones en las que se manifiesta la acción colectiva (social), y en las cuales se estructura la sociedad humana y los comportamientos individuales y colectivos.

Pero permítanme afirmar que los seres humanos parecen ser hoy más "sociales" que "libres". Quiero decir que habitualmente, y en la gran mayoría de las situaciones y de los casos, las personas actúan condicionadas socialmente, fuertemente determinadas por la colectividad de la que forman parte, conformándose según las exigencias y los requerimientos de la economía, del orden político (institucional, jurídico, etc.) y del contexto cultural en los cuales nacen, crecen y se educan. La libertad individual se manifiesta siempre, pero habitualmente en los hechos pequeños, en las decisiones menores, mientras que en las grandes direcciones que implican procesos históricos, estructurales, civilizatorios, siguen normalmente las direcciones establecidas y actúan "socialmente" (como "hombres masa"). Pongo un ejemplo: como “consumidores" los modernos se comportan como "masa”, siguiendo criterios semejantes y comunes en cuanto a la racionalidad y a la lógica con que actúan. Como individuos "libres" toman decisiones diferenciadas escogiendo las marcas de los productos particulares en los estantes del supermercado. Por esto es tan difícil actualmente crear una 
nueva economía, una nueva civilización, una nueva “segunda naturaleza”, y un nuevo tipo de consumidor como integrante de ella.

En este punto se habrá ya comprendido que crear una nueva y superior civilización consiste, en última síntesis, en la creación de una nueva y superior "segunda naturaleza” en los seres humanos. Que ello sea posible (si bien sumamente difícil) estaría en la "naturaleza humana” esencial, en cuanto deriva de la racionalidad y libertad, y del hecho de que somos "sociales” y por tanto capaces de construir procesos y organizaciones económicas, políticas y culturales.

Pero para iniciar la creación de esta “segunda naturaleza” nueva y superior, basada también ésta sobre la "naturaleza humana” esencial, es necesario separarse y tomar distancia respecto a la "segunda naturaleza" actualmente predominante.

\section{¿Es posible -y ¿cómo?- la creación de una nueva "segun- da naturaleza", o sea un cambio profundo en el modo de ser y comportarse de las personas?}

Teóricamente es posible en cuanto en la “naturaleza humana” básica está la libertad, la posibilidad de decidir, y por ello siempre existe la posibilidad de la autonomía respecto de la "segunda naturaleza” dada. Una nueva "segunda naturaleza" es posible en cuanto los hombres pueden decidir, escoger, crear, y orientarse por sí mismos; y es posible también que tal nuevo modo de ser se generalice, por cuanto la libertad individual está limitada por condicionamientos, influencias, contextos, poderes, etc. que podrían ir cambiando.

Sin embargo, para iniciar la creación de una "segunda naturaleza” es ante todo necesario que algunos individuos alcancen la autonomía (mediante su propia racionalidad y libertad) respecto a la "segunda naturaleza" predominante. Estos individuos, organizados en redes y potenciándose recíprocamente, podrán luego expandir el nuevo modo de ser y de comportarse, a través de acciones y procesos sociales, económicos y políticos que impulsen coherentemente. Pero el hecho que hay que asumir es, primero, que el inicio de la creación de una nueva civilización es hoy, tal como lo ha sido en el pasado, un proceso iniciado por pocos, porque son pocos los que aplican la libertad a las grandes direcciones del propio vivir y no limitadamente a decidir sobre cuestiones secundarias en un marco socialmente establecido y predeterminado.

Para que los individuos puedan iniciar la creación, en sí mismos, de una nueva "segunda naturaleza”, es necesario que se conecten con la primera naturaleza, haciéndose libres, racionales y sociales. Si no nos conectamos con nuestra "naturaleza humana” esencial, no podemos iniciar la creación de una nueva y superior “segunda naturaleza”. En particular, la crea- 
ción de un nuevo tipo de consumidor supone desprenderse de aquella "segunda naturaleza" que se manifiesta en el consumidor moderno. Pues bien, para desprenderse y liberarse de tal "segunda naturaleza" es necesario que establezcamos contacto con nuestra íntima "naturaleza humana" esencial, y su correspondiente estructura esencial de necesidades.

Tomar contacto con nuestra íntima "naturaleza humana” esencial no es sencillo, porque ella se encuentra escondida y oprimida bajo la "segunda naturaleza" que la civilización capitalista y estatista ha construido en nosotros; por esto es preciso comenzar con la conquista de la autonomía respecto de esa "segunda naturaleza" y de los modos de pensar y de comportarse propios de la vieja civilización.

Un elemento primordial de esta conquista de la autonomía consiste en des-cubrir y reconceptualizar las necesidades y su modo de ser y de manifestarse, tal como se dan al nivel de nuestra "naturaleza humana" esencial. En otras palabras, conectarse con nuestra "naturaleza humana" esencial implica ante todo tomar conciencia de la forma verdaderamente humana -racional, libre y social- en que se manifiestan nuestras necesidades, aspiraciones y deseos.

Ha sido en este sentido que, para fundamentar la propuesta de una Economía de Solidaridad y Trabajo fundamentada en una más amplia Teoría Económica Comprensiva, hemos elaborado una nueva concepción de las necesidades humanas. El fundamento filosófico de esta nueva concepción de las necesidades humanas es una concepción del hombre distinta y distante de las concepciones positivistas (subjetivistas, relativistas o materialistas) que han predominado en la civilización y en la economía modernas y que dieron lugar tanto a la idea liberal como a la concepción colectivista de que las necesidades humanas.

En la Teoría Económica Comprensiva nos basamos en una concepción del hombre que reconoce tanto al individuo como sujeto libre y racional, capaz de hacerse y modificarse a sí mismo en base a sus propias formas de conciencia, a sus decisiones libres y a su voluntad particular, como también a la sociedad humana que como especie o colectividad evoluciona y se auto-organiza a través de procesos económicos, políticos y culturales complejos y cambiantes. En tal sentido, reconocemos aquello que proponen como conocimiento verdadero las concepciones positivistas modernas (relativistas, deterministas e historicistas); pero todo ello lo integramos en una visión comprensiva, en la cual no negamos la existencia de una "naturaleza humana” esencial. En este último sentido, recuperamos aquello que aporta la tradición filosófica que viene desde Aristóteles y que fecundó a las grandes filosofías antiguas y medievales, que sostienen que el ser humano posee una esencia natural, o una "naturaleza humana" esencial, de carácter no puramente biológico sino también espiritual, que es común a todos y a cada uno de los individuos.

¿Cómo se integran y hacen coherentes la afirmación de que los seres humanos se hacen a sí mismos como individuos libres, que configuran sus 
propias estructuras de necesidades y que en dicho proceso se diferencian indefinidamente, con la concepción de una esencia natural, o de una "naturaleza humana” esencial y común a todos los individuos?

La idea de una esencia del hombre o de una "naturaleza humana" esencial ha sido criticada en la filosofía moderna precisamente porque no podría reconocer adecuadamente la dinámica de la existencia humana y de la historia, ni comprender el profundo significado de la subjetividad y libertad características de la experiencia del individuo moderno y de las organizaciones social e históricamente determinadas. Pero podemos superar esta crítica -que es válida en cuanto se piense en una "naturaleza humana" inmutable y completamente definida- en la medida que desarrollemos teóricamente una idea presente pero no desplegada por la filosofía aristotélica y sus derivaciones medievales, a saber, que la naturaleza esencial del hombre, con ser tal y precisamente por serlo, se encuentra en los individuos y grupos reales y particulares, como la potencia de un acto siempre imperfectamente realizado.

De esta manera, la experiencia diferenciada de los individuos y la diversificada evolución histórica de la sociedad, se entienden como el proceso de realización o actualización progresiva de una esencia inconclusa. Se supera así de manera radical la supuesta estaticidad de la concepción de la "naturaleza humana" esencial, toda vez que sin negar que los seres humanos posean una esencia o naturaleza común, se la concibe en permanente construcción, como un proceso y no como un dato.

Con esta forma de concebir la "naturaleza humana" esencial, no solamente quedan reconocidas la subjetividad individual y la historicidad social, sino que ellas aparecen y se hacen presentes en un nivel de profundidad y radicalidad mucho mayor, incluso insospechada por las propias concepciones subjetivistas e historicistas modernas. En efecto, la subjetividad de los individuos y la historicidad de la especie o sociedad, no se aprecian solamente como datos empíricos sino que se los reconoce esencialmente, o sea en lo más radical y profundo del propio ser humano, con la consecuencia que el mismo proceso de realización y actualización de la esencia humana es obra de su propia libertad, subjetividad e historicidad.

Según este modo de concebirla, la "naturaleza humana” esencial se manifiesta como esencial y constitutivamente abierta, y el proceso de su actualización como la realización de un proyecto que se encuentra sujeto a su propia y libre subjetividad, que se cumple progresivamente en la historia y la evolución de las formas sociales y de las civilizaciones humanas. La apertura, sin embargo, no es absoluta, o sea no se trata de indeterminación pura, pues la esencia o naturaleza constitutiva del hombre, por abierta y potencial que sea, es también de alguna manera acto, realidad constituida en algún grado o medida (el acto de su potencia, diríamos en lenguaje aristotélico), lo que en otras palabras significa que la experiencia individual y social humana 
está volcada y llamada a realizar lo que potencialmente es el hombre, y no cualquier cosa.

Y es en este proceso de actualización y realización de la propia esencia o "naturaleza humana”, que se van constituyendo históricamente, como fruto de la libertad y racionalidad humana en su evolución social e histórica, las “segundas naturalezas” de que hemos hablado. Cada una de éstas, enraizada en, y expresión parcial de, la “naturaleza humana” esencial. Y cada una de ellas dejando su huella, sus sedimentos, sus avances, logros y progresos, en la esencia humana o "naturaleza humana” esencial. De este modo ésta va evolucionando, transformándose, perfeccionándose progresivamente.

Por ejemplo, la conformación del individuo moderno, como sujeto de legítimos intereses y derechos individuales, y la concepción de la sociedad humana como realidad que debe garantizar derechos y necesidades fundamentales comunes para todos, serían logros definitivos, realizaciones consolidadas, en cuanto expresiones de la actualización de lo que estaba anteriormente sólo en potencia.

\section{¿Cómo impacta esta concepción de la "naturaleza humana” sobre la cuestión de las necesidades?}

De acuerdo a nuestra concepción del hombre y de la economía, lo primero es pensar que las necesidades humanas no son lagunas ni vacíos que hay que llenar, de modo que no son determinables desde los productos que vayan a completar tales vacíos y a satisfacer esas carencias. Las necesidades son una expresión de la voluntad de realización inherente a la esencia de la persona humana, en niveles crecientes y cada vez más amplios. Son los detonantes de las actividades y procesos tendientes a convertir en acto lo que está solamente en potencia, como virtualidad, en cada individuo y en cada grupo. Concebimos las necesidades como manifestaciones de la esencia humana que busca desplegarse, completarse, potenciarse. Expresan la voluntad de ser, o sea la intención de la "naturaleza humana” esencial presente en cada individuo, en cada colectivo y en la sociedad entera, orientada o volcada hacia su más plena realización.

Debemos sacarnos de la mente el pensar las necesidades como las necesidades de los animales, porque esa idea con que se ha trabajado en la economía moderna, que las entiende como carencias que se resuelven con objetos, es lo que ocurre a los animales. Estos, en cuanto seres fundamentalmente corpóreos que viven solamente en el nivel fisiológico y en el ámbito de las sensaciones, experimentan de ese modo las necesidades. Y ¿cuál es la imagen que nos viene a la mente en forma inmediata cuando pensamos en las necesidades humanas de dicho modo? La necesidad de comer, que compartimos con los animales y que experimentamos de manera parecida (aunque con notables diferencias) a como la viven los animales.

Pero el hombre y la mujer tenemos algo esencial que nos distingue: somos de otro orden, estamos dotados de racionalidad y de libertad. Pienso 
que el comienzo de la posibilidad de pensar con un nuevo paradigma radica en el redescubrimiento del ser humano como una realidad esencialmente espiritual; pero entendiendo el espíritu no en sentido etéreo, angélico o de algo que es inaprensible e inobservable, sino en el sentido de una realidad que es objetiva y que se subjetiva en las personas concretas, corpóreas, que somos cada uno de nosotros. De aquí derivan algunas precisiones sobre las necesidades en cuanto específicamente humanas:

\section{a) Las necesidades se experimentan en el plano de la conciencia.}

Aún aquellas necesidades que son corporales, como la de alimentarnos, se viven subjetivamente, concientemente, y se experimentan en el plano del espíritu. No es simplemente una necesidad biológica, como no es una necesidad puramente biológica la necesidad sexual; como no es puramente biológica la necesidad de curar una herida. En el ser humano todo ocurre y todo se vive concientemente, es decir, secuencial o concomitantemente en el plano interior y en el plano corporal, y en ambos planos se busca encontrar la satisfacción de la necesidad.

\section{b) Las necesidades son energías, son potencias que buscan su actualización.}

Asociado a lo anterior está el hecho que las necesidades no se presentan como vacíos que llenar, sino como energías que se despliegan. Son potencias, son fuerzas que buscan su satisfacción. Son vectores direccionados, en el sentido de que están buscando activamente algún logro, algún resultado para el individuo o para el grupo.

\section{c) Las necesidades se satisfacen en el despliegue de la energía que contienen.}

Son energías, pero son también energías capaces de autosatisfacerse. Es decir, la necesidad no necesariamente se satisface mediante algo externo, sino que el propio despliegue de su energía significa la satisfacción de la necesidad. Es así al menos en muchas de ellas, o tal vez en todas desde cierto punto de vista, o a partir de cierto nivel de satisfacción. Por ejemplo, la necesidad de conocimiento se satisface no a través del conocimiento formulado y ya construido que se le presenta a la persona para que lo memorice, llenando así su ignorancia pensada como el vacío que llenar. La necesidad de conocimiento la satisface la construcción activa de un conocimiento, que puede utilizar o emplear como insumo o como componente algún conocimiento que otros han elaborado anteriormente; pero no se produce ningún efecto en el sujeto si éste no lo reconstruye mediante su propia acción de aprendizaje. Sólo si el individuo la realiza activamente, esa necesidad es satisfecha. Lo mismo pasa con todas las necesidades.

\section{d) Las necesidades se reproducen y potencian al satisfacerse.}

Las necesidades, como energías que se autosatisfacen, son también 
energías que se auto-reproducen, o sea, no es que las necesidades sean simplemente recurrentes, como cuando algo que se llena después se vacía, por lo tanto hay que volver a llenarlas. No se trata de recurrencia, sino que hay una reproducción de las necesidades. Y para reproducir una necesidad es necesario que la necesidad haya sido desplegada y haya sido satisfecha. Por ejemplo, una persona tiene necesidad de lectura, de leer novelas, poesía, y de escuchar música, etc. Esas necesidades las desarrollamos y perfeccionamos en la medida que leemos, que escuchamos música, que estudiamos. Desarrollamos las necesidades estéticas en la medida que observamos (o mejor aún, que creamos) pinturas, esculturas, en que vamos a museos, en que nos cultivamos.

\section{e) Las necesidades son fuerzas constructivas y no debilidades que habría que subyugar.}

Existe un concepto de las necesidades -que podemos caracterizar por su conexión a las concepciones budistas- que apunta en una dirección distinta de lo que estamos diciendo pero que se conecta y puede ayudarnos a concebir bien las necesidades humanas. Señala ese concepto que el único estado de plena satisfacción en que puede encontrarse un ser humano es cuando ha logrado anular sus necesidades. O sea, el estado de satisfacción es un estado de no-necesidades.

Es interesante prestar atención a esa manera de concebir las necesidades humanas; pero prestarle atención no significa asumir esa concepción. Pienso más bien que las necesidades humanas debemos pensarlas en términos de energías positivas, no de energías negativas, de modo que no imaginemos el estado de satisfacción como una situación de apagamiento de las necesidades, de no desear nada y por ello estar satisfecho. Creo que eso no es una buena antropología. Si bien el ser humano puede, con disciplina y esfuerzo interior, apagar sus necesidades, detener su acción y quedar en cierto modo “en paz” consigo mismo, eso no implica necesariamente aproximarse a la realización de la "naturaleza humana” esencial. Podría pensarse también como una suerte de retroceso a un estado de intimidad original, pero no de realización o de expansión. (Diferente es el caso en que la disciplina y la marcha atrás se refieran a necesidades artificiales construidas en el marco de una "segunda naturaleza" inferior que hay que superar. Pero en tal caso se trataría de reemplazar una necesidad inferior por otra superior y no del anulamiento de la necesidad).

\section{f) Las necesidades contienen el proyecto de su cumplimiento.}

Nuestra formulación de las necesidades está direccionada al potenciamiento del ser humano. Incluso diría (como una especie de afirmación que resume este concepto de necesidades que estoy tratado de expresar) que las necesidades son proyectos, o dicho aún más ampliamente, que las necesidades contienen el proyecto de su cumplimiento, no de su apagamiento. 
Las necesidades en este sentido son fuerzas constructivas, en cuanto son la expresión de lo que está en potencia - en cada momento y en cada situación y en cada contexto - en las personas, que queremos ser más que los que somos. Y ese querer ser más de lo que somos, es lo que produce una insatisfacción. Pero una insatisfacción con respecto a lo que ya somos como resultado de algo anterior logrado, que en cierto modo nos permite estar contentos, estar satisfechos. Pero al mismo tiempo nos hace estar insatisfechos porque queremos ser más, queremos expandir nuestra conciencia, tenemos un espíritu que no se contenta nunca con lo que ha logrado.

Entonces la insatisfacción es, desde ese punto de vista, un estado que apreciamos como momento positivo, mientras que el estado de satisfacción como apagamiento de la necesidad nos detiene. En cambio, si la necesidad la pensamos como un proyecto -de hecho los seres humanos vivimos las necesidades como proyecto, incluso la necesidad de alimentarnos incluye el proyecto de la comida que tenemos que preparar y organizar para satisfacer esa necesidad- entonces la insatisfacción no es negativa, aunque es como el dolor. El dolor incentiva, mueve, si no tuviéramos dolor de ningún tipo, nos detendríamos. ¿Por qué los animales no hacen historia? ¿Por qué no hacen economía? ¿Por qué no tienen proyectos? ¿Por qué no construyen? Bueno, porque sus necesidades son experimentadas como esas demandas de satisfacción, como esos vacíos que se llenan con lo que ya se encuentra preparado en la naturaleza. En la satisfacción de las necesidades de los animales no hay proyectos, de modo que sus necesidades se mantienen siempre iguales, son recurrentes siempre al mismo nivel.

Provistos de estos conceptos podemos pensar un camino nuevo para superar los límites del crecimiento en que se encuentra la economía y para abrir ese horizonte cerrado en que pareciera que estamos actualmente. Hay quienes dicen que la manera de resolver el problema de la sustentabilidad del crecimiento, del agotamiento de los recursos, del deterioro del medio ambiente, va en la dirección de que nos convirtamos en seres con cada vez menos necesidades. Obviamente si tenemos menos necesidades demandamos menos productos, y por lo tanto podemos producir menos, acumular menos y desgastar menos los recursos. Pero eso es caminar en una dirección que no constituye un horizonte abierto, no es una perspectiva de gran iluminación para la experiencia humana. Es un futuro bastante oscuro, de retroceso, no de verdaderos avances hacia experiencias superiores, porque se sigue pensando las necesidades como vacíos que hay que satisfacer llenándolos con algo, o que hay que tratar que olvidar que existe o mantener bajo control de modo que exija menos y se satisfaga con menos bienes y servicios.

Pienso que hay una salida distinta al tema, que no niega el perfeccionamiento humano, que no niega la expansión, que no niega la creatividad, que no niega el futuro, que no niega que la experiencia humana pueda descubrir horizontes nuevos, desconocidos. Y eso pasa 
por pensar las necesidades de otra manera, lo cual a su vez revierte sobre el tipo de producción y también sobre el modo como se usarán los recursos.

\section{La "naturaleza humana" esencial busca su realización por las cuatro dimensiones de la experiencia humana en que surgen las necesidades}

Hemos visto que las necesidades son fuerzas -energías direccionadas- cuyo despliegue da lugar a experiencias individuales y colectivas en las que el hombre y la sociedad van desarrollando la "naturaleza humana” esencial, en sus diferentes dimensiones. Podemos imaginar estas energías originándose -como vectores de fuerzas- a partir de un punto cero en el cual no hay aún ningún despliegue, o sea que están en potencialidad pura. A nivel individual ese punto inicial sería el del nacimiento, y a nivel colectivo, la conformación del primer grupo humano que haya aparecido en la tierra. En dicho punto inicial no hay aún realización lograda, pero en él comienzan las experiencias que dan lugar a los procesos de expansión, de crecimiento, de perfeccionamiento humano. Ese conjunto de vectores que se abren y extienden progresivamente en todas las direcciones, constituyen las experiencias que formalmente las podemos concebir como de satisfacción de las necesidades humanas.

Observamos que dichas dimensiones esenciales las podemos reunir en cuatro conjuntos principales, en los que se forman y despliegan las necesidades, aspiraciones y deseos humanos. Ellas son: las del cuerpo (dimensión corporal), las del espíritu (dimensión cultural), las del yo individual (dimensión personal) y las de las colectividades (dimensión social). Como las energías (vectores) se despliegan en varias direcciones, podemos representar las cuatro dimensiones esenciales en una figura en la cual se cruzan dos ejes principales. (Figura 1)

Hay un eje (o dos direcciones polarmente dispuestas) que es el de las necesidades que se dirigen, por un lado, hacia el yo o hacia lo individual, o que expresa el proceso de desarrollo de la individualidad, el proceso de afirmación de la identidad personal, el proceso de cumplimiento de las necesidades que cada uno tiene en función de sí mismo, y por el otro lado está el vector que se orienta en la dirección de lo social, de los otros. Son las necesidades de individuación y de socialización (o sociabilidad).

En otro sentido tenemos el segundo eje cuyas polaridades serían, por un lado la corporalidad, con las necesidades que tenemos como cuerpo que somos y que tiene sus propias energías, sus propios proyectos, sus propias necesidades, y por el otro lado la espiritualidad o las necesidades culturales, las necesidades de conocer, de crear, de trascender, 
las necesidades de encontrar algo que va más allá de lo tangible, de lo empírico, de lo material, de lo corpóreo, y de cultivar el espíritu.

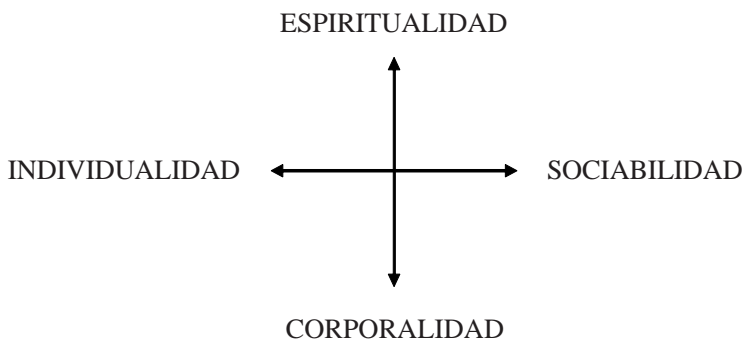

En estas cuatro dimensiones en las cuales el ser humano se va realizando y desplegando, se pueden instalar o identificar todas las necesidades que tenemos. Hay necesidades de personalización, de individuación, de conservación de sí mismo, de autoafirmación, de obtención de seguridad, como hay también necesidades de compartir, de convivir con otros, de vincularse, de amar, de ser amado, de integrarse a la sociedad, de participar en organizaciones y en colectivos. Hay necesidades que están integradas a nuestra dimensión corpórea, a nuestro cuerpo, y hay necesidades que están asociadas a nuestra búsqueda de cultura, de trascendencia, de valores superiores, de conocimiento, etc.

Estos cuatros vectores son dimensiones de la experiencia del sujeto como individuo. Pero sujetos de las necesidades que se expresan en la economía no son solamente los individuos. En efecto, también la familia tiene necesidades, una comunidad tiene necesidades, una organización humana, un grupo, una nación, la sociedad en general, son también sujetos de necesidades. Son sujetos de necesidades, independientemente del grado de asociación o del tamaño que tengan estos sujetos, desde el individuo hasta la humanidad o la especie humana como un todo. Y todos estos sujetos manifiestan las mismas cuatro dimensiones de la experiencia humana que buscan realizar al sujeto.

Así, como familia o como nación, tenemos necesidades de identidad, pero también de participación con otras familias o naciones; tenemos necesidad de afirmación de nuestra realidad física territorial, como también de nuestra identidad espiritual, de nuestros valores. Son los mismos ejes, que los podemos pensar en cualquier nivel en que imaginemos la construcción de un sujeto colectivo, y también para cada individuo.

Ahora bien, el proceso de la vida humana, el proceso de desarrollo histórico, es un proceso de expansión y de realización en cada una de estas direcciones. Pero también, en tales procesos las necesidades pueden distorsionarse, desviarse e implicar retrocesos. Se va avanzando o retrocediendo en estas cuatro direcciones, se va creciendo o reduciendo en ellas 
en el tiempo. En las cuatro dimensiones del cuerpo, del espíritu, de la individualidad y de la sociabilidad, se es en los orígenes como un punto, del que parten los vectores del desarrollo, en los cuales aparecen las necesidades que corresponden a los procesos de realización de los sujetos en esas diversas dimensiones constitutivas esenciales. La satisfacción de las necesidades - de cada necesidad- es un pasar de la virtualidad o potencia de realización, al acto como realización cumplida en un cierto nivel.

Pero este pasaje se cumple a través de una acción -la actividad de consumo-, que implica el operar de alguno o de alguna cosa que esté ya en acto (el mismo sujeto, otras personas, los bienes y servicios consumidos, etc.). (En este sentido, me conecto con la concepción del gran Aristóteles, que explica como cada movimiento o pasaje de la potencia al acto, es decir, cada movimiento de realización de aquello que se encuentre precedentemente en estado de virtualidad, requiere un agente, un motor, la acción de algo capaz de empujar, atraer o mover, lo cual debe necesariamente estar ya en acto, o sea, debe ser capaz de actuar, y no ser ello mismo solamente potencialidad pura).

El punto que es inicialmente el cuerpo se despliega por la acción del cuerpo de la madre que le proporciona la materia celular y el alimento, y luego se nutre de otros cuerpos que incorpora como alimentos, estímulos, etc. Sólo a partir de cierto grado de actualización de sus potencias el niño está en condiciones de desplegar sus propias energías para continuar desarrollándose y perfeccionándose. Análogamente ocurre con la dimensión espiritual, donde por ejemplo la capacidad intelectiva se encuentra en los comienzos vacía, como "tabula rasa”, sin imágenes, sin recuerdos, ideas ni conceptos. Es el estímulo externo que le llega por los sentidos lo que la abre a los primeros conocimientos elementales, y es la enseñanza que recibe del entorno y por la mediación de otras personas lo que la conduce a los primeros conocimientos abstractos. Sólo cuando ha alcanzado cierto grado de desarrollo de sus propias capacidades cognitivas está en condiciones de desplegar su intelecto activo y creativo, a pensar e investigar por su propia cuenta. Lo mismo puede decirse de la individualidad y de la sociabilidad. Inicialmente no puede decirse que el hombre sea en propiedad o en acto un individuo, que supone autoconsciencia de su distinción y separación respecto a otros y de su identidad y unidad en sí mismo: lo es potencialmente,, y actualiza dicha potencialidad, o sea se individualiza y se reconoce como un yo distinto a las demás personas, por la presencia de éstas en las que va reconociendo a sus iguales al mismo tiempo que las percibe diferentes, experimentando así, en y por su relación con otros individuos, su propio proceso de individuación. Ya constituido como individuo en cierto grado, está en condiciones de continuar por sí mismo su proceso de personalización y autoconciencia individual. Tampoco puede decirse que el hombre sea ya en el momento de nacer un ser social en acto, participante en comunidad y sociedad; lo es potencialmente, y en ellas es progresivamente integrado por otras personas, a partir de la familia en que nace y crece, y sólo habiendo sido integrado a la sociedad en cierto nivel puede desplegar en ésta su propia potencialidad creadora de sociabilidad. 
La satisfacción de las necesidades a través del consumo es, pues, un proceso extraordinariamente rico de contenidos, y de la mayor importancia para el desarrollo humano y la realización del hombre conforme a su "naturaleza humana” esencial. Desde esta perspectiva, organizar y realizar dicho proceso de consumo de manera racional e inteligente se convierte en asunto crucial.

\section{Con esta concepción de la "naturaleza humana” esencial se resuelve la controversia entre las posiciones liberal y colectivista sobre las necesidades y el consumo}

El modo en que hemos reformulado las necesidades, poniéndolas en la óptica de la realización de la “naturaleza humana” esencial, nos permite resolver de un modo nuevo la cuestión económica en que se han confrontado las visiones liberal y colectivista, a las que hicimos referencia al iniciar el análisis, a saber, la cuestión de si las necesidades sean pocas y comunes a todos, o bien diferenciadas individualmente en términos que solamente cada sujeto puede determinarlas. En efecto, conectar las necesidades con la "naturaleza humana” en orden a su realización en las cuatro dimensiones esenciales de la experiencia humana, nos permite comprender que hay un plano en el cual podemos identificar lo que es común a todas las personas y a todos los sujetos, y otro nivel en que se presentan las necesidades, aspiraciones y deseos que nos distinguen y diferencian individualmente.

Ante todo, el hecho de tener necesidades en estas cuatro dimensiones es común a todos los seres humanos, pues todos tenemos necesidades corporales, necesidades culturales o espirituales, necesidades sociales y necesidades individuales. Pero no sólo esto, sino además, comprobamos que en cada una de esas dimensiones de la experiencia es posible identificar un umbral básico de satisfacción indispensable, donde se presentan necesidades comunes y compartidas por todas las personas.

Así, por ejemplo, en la dimensión corporal, todos tenemos necesidad de un nivel básico de alimentación y nutrición, de protección frente a las condiciones climáticas (me refiero a la vivienda básica y al abrigo, entre otros bienes), que garanticen el crecimiento sano del individuo y su subsistencia. En la dimensión espiritual, el nivel de necesidades básicas y comunes a todos puede estar dado por la alfabetización, o por un nivel de enseñanza general, por el acceso a la información socialmente disponible, por la libertad de pensamiento y de culto, etc. En la dimensión individual, necesidades básicas comunes serían la protección frente las agresiones físicas, acceso a servicios de salud, etc. En la dimensión social, la necesidad de comunicarse libremente, de participar en organizaciones, de crear una familia, etc.

Estos ejemplos con los que ilustramos el nivel de necesidades comunes a todos en cada una de las dimensiones de la experiencia, nos hacen ver que dicho umbral de satisfacciones mínimas va experimentando cambios en el tiempo: se va elevando el nivel de satisfacción de las necesidades 
que se considera el mínimo aceptable que es necesario garantizar para todos los individuos. Las sociedades suelen institucionalizarlos y darles valor jurídico, considerándolos como “derechos” que tienen los individuos y que la sociedad debe garantizar.

Pues bien, ¿cómo se conecta y explica esto desde la óptica de la “naturaleza humana” esencial? Pues, claramente, se trata del proceso de actualización progresiva en el tiempo de esta "naturaleza humana”, de la cual hemos observado que se encuentra en proceso de realización progresiva, proceso guiado por los propios sujetos organizados en sociedad. A medida que se despliega la "naturaleza humana” esencial en sus cuatro dimensiones, dicha "naturaleza humana” se va completando, perfeccionando, y actualizando aquello que en fases anteriores se encontraba solamente en potencia. Así, por ejemplo, si en la dimensión espiritual o cultural en cierta etapa la necesidad común está dada por la alfabetización, en otra fase más avanzada puede tratarse del acceso a cierto grado de educación y conocimiento de las artes, las letras y las ciencias. Así, en cada una de las dimensiones, la "naturaleza humana” va realizando sus virtualidades, de modo que aparecen progresivamente nuevas necesidades que se convierten en patrimonio común para todos. En este sentido, podemos decir que la humanidad va “conquistando” nuevos espacios de necesidades en los que la "naturaleza humana” esencial se va enriqueciendo, ampliando, perfeccionando.

El plano de las necesidades, aspiraciones y deseos individuales, en que cada sujeto tiene legítimo derecho y oportunidad de buscar satisfacción de manera libre e independiente, resulta determinado también por la “naturaleza humana” en el proceso de despliegue de sus cuatro dimensiones esenciales. Cualquiera sea el nivel de realización alcanzado socialmente, o mejor dicho, dado un determinado nivel de realización común a todos, los individuos, las familias, las organizaciones, las colectividades de cualquier tamaño, continúan expandiendo siempre su naturaleza esencial, haciendo surgir sus propias y nuevas necesidades y demandas, que se manifiestan como sus proyectos, sus vocaciones, sus aspiraciones, sus deseos de realización y perfeccionamiento. Avanzando así en el despliegue individual de las necesidades en sus cuatro dimensiones, los individuos (especialmente los más dinámicos y creativos) van abriendo el camino a realizaciones que luego, con el tiempo, progresivamente, podrán estar disponibles para todos e implicar un avance general de la “naturaleza humana” esencial.

\section{Se explican también las grandes diferencias que se obser- van entre los individuos, derivadas del modo en que enfrentan y satisfacen sus necesidades}

Las grandes diferencias que se observan entre un individuo y otro en cuanto a su desarrollo en las dimensiones corporal, espiritual, individual y social, encuentran también su explicación a partir de la concepción de la "naturaleza humana” esencial, entendida como un proceso en curso de rea- 
lización y cumplimiento en base al surgimiento y evolución de las necesidades humanas que manifiestan los individuos y los grupos.

Hay atletas de notable desarrollo y flexibilidad física, como también hay sabios de gran profundidad espiritual; hay sujetos sumamente individualistas que ponen su ego por encima del mundo, como hay otros generosos que entregan su vida por causas sociales. Todos ellos son personas que expresan la misma "naturaleza humana" esencial, y todos ellos han experimentado algún grado de desarrollo en las cuatro dimensiones de la experiencia humana. La diferencia notable entre ellos, está precisamente en que han desplegado de maneras muy distinta estas cuatro dimensiones, haciendo presente en sus vidas las diferentes necesidades con diversa intensidad y satisfaciéndolas de maneras sumamente diferentes.

$\mathrm{Al}$ nacer, todos ellos eran pura potencialidad en las cuatro dimensiones, como un punto no desplegado; si bien probablemente esas potencialidades estaban ya diferenciadas en cuanto a la fuerza con que pudieran desplegarlas. Me refiero a una cierta predisposición, en la cual pudieran influir condicionantes genéticos de los individuos que los hicieran más o menos aptos para desarrollar con mayor o menor facilidad esas diferentes experiencias y necesidades. Por otra parte, el entorno socio-cultural en que hayan nacido, también les facilitará o dificultará su desarrollo en unas y otras dimensiones. Este entorno a contexto socio-cultural, de algún modo constituyente de la que hemos denominado una "segunda naturaleza", establece algo así como un "piso" o base al que aceleradamente llegarán los individuos mediante su inserción en la sociedad, partiendo de la familia, la escuela, el vecindario, la nación, etc.

De este modo se predisponen los individuos, dotados de una misma "naturaleza humana" esencial, para desplegarla de formas y en niveles muy diferenciados. Se predisponen, genética y socialmente; pero el proceso de desarrollo en las cuatro dimensiones comienza con la interacción y el relacionamiento concreto. En los inicios y hasta cierto nivel, el proceso de desarrollo estará fuertemente inducido desde fuera, o sea, desde las personas y contextos que irán proveyendo diferentes respuestas y satisfactores ante las necesidades que en cada una de esas dimensiones se irán inevitablemente presentando.

Pero llega un momento en que cada sujeto estará en condiciones de ir tomando el control de su proceso de desarrollo a través del consumo. Y entonces se acentuará la diferenciación, en cuanto los individuos y los grupos irán avanzando por estas diferentes dimensiones con distinto ritmo y diferentes énfasis, como resultado de las opciones que irán efectuando en cuanto a las necesidades que privilegiarán satisfacer con los recursos y en los tiempos disponibles por cada uno, y según los bienes, servicios y satisfactores que irán escogiendo.

De este modo, una persona puede ir enfatizando fuertemente la dimensión de su corporalidad, y convertirse en un gran deportista o en al- 
guien que potencia su físico y sus diversas dimensiones corporales, mientras que otras personas pueden mantener cierta atrofia en esas dimensiones e ir desarrollando más fuertemente las dimensiones culturales, del conocimiento, de la espiritualidad. Una persona puede estar muy enfatizada en la perspectiva de lo individual, en la afirmación de sí misma, de su identidad, de su yo, de su seguridad y de sus propios intereses. Y otro puede estar muy orientado a hacia los demás, volcado a compartir, a participar, a estar y actuar junto con otros.

Naturalmente que todos vamos, de alguna manera desde que nacemos, avanzando en estas distintas dimensiones. Pero nos vamos determinando con una cierta personalidad, con una cierta estructura personal de necesidades, en función de cuánto avanzamos en cada una de estas direcciones. Hay personas con fuertes necesidades de individuación y grandes exigencias corporales, y otras con marcadas necesidades de sociabilidad y acentuadas demandas culturales. Las combinaciones posibles son infinitas, configurando múltiples estructuras de personalidad y de necesidades, que van resultando de cuánto y de cómo cada uno haya ido desarrollando las experiencias.

Cuando un sujeto -individual o colectivo- enfatiza una cierta dirección en su desarrollo, puede ocurrirle que descuide otras dimensiones. Entonces, cabe preguntarse: ¿cuál es la mejor estructura de personalidad? Probablemente se responda que la mejor estructura es la de alguien que las haya desarrolla todas en forma equilibrada, esto es, cuya personalidad evidencie una perfecta armonía y equilibrio entre todas las dimensiones de la experiencia humana. Pero ésta pudiera ser una respuesta incompleta, o incluso engañosa.

En efecto, puede ocurrir que una persona que desarrolla en forma equilibrada todas las necesidades no destaque ni aporte especialmente en ninguna de las dimensiones de la experiencia humana. A la inversa, por ejemplo, la selección de fútbol de un país requiere personas que dediquen ocho horas al día al desarrollo de la musculatura y de sus habilidades físicas, y tantas horas más a pensar en esa actividad, mientras que un líder político o un maestro espiritual tendrá que haber puesto énfasis en otra dimensiones, aunque quizá haya tenido que experimentar cierta atrofia en su dimensión corporal.

Lo que quiero decir es que hay aquí un mundo de opciones libres, legítimas. No hay un modelo. Claro, hay un modelo de perfección ideal, que pudiera expresarse con la siguiente afirmación: "Perfecto es el que lo integra todo, llegando en todo a la excelencia”. Pero se sabe que algunos grandes hombres son medios tullidos, por ejemplo. Y se discutiría también que un maestro espiritual tenga una muy fuerte orientación hacia sus intereses particulares.

Habrá que diferenciar la perfecta realización de la "naturaleza humana” esencial que podemos construir como sociedad, de aquello que cada individuo y grupo humano particular pueda desarrollar. A nivel individual, 
podemos pensar que en cualquiera de las cuatro dimensiones que enfaticemos, o que desarrollemos con más energía, estaremos acercándonos, por lo menos en esa dimensión, a algún nivel de perfección.

Por eso, lo que quiero aquí relevar y poner de manifiesto es la legitimidad de las opciones individuales y la validez del desarrollo de personas y de sujetos que no sean necesariamente equilibrados, en el sentido de que desarrollen en forma simétrica las diferentes dimensiones. En todo caso, cada uno de nosotros, en cualquiera de ellas, todavía podemos avanzar mucho.

\section{Completamos este análisis de las dimensiones de la experiencia humana en las que se presentan las necesidades, agregando cuatro importantísimas observaciones}

\section{a) Complementariedades, articulaciones, sinergias.}

Un primer complemento del análisis, necesario para alcanzar una adecuada comprensión de la "naturaleza humana" y de sus necesidades esenciales, nos lleva a precisar que las cuatro dimensiones de la experiencia que hemos identificado y representado en dos ejes que se cruzan al centro, desde el cual se despliegan en direcciones polarmente dispuestas, están en realidad estrechamente articuladas, interactúan entre ellas, se pueden recíprocamente bloquear o, al contrario, potenciar sinérgicamente unas con otras. Hemos puesto el ejemplo de una bailarina que en la expresión de su oficio o de su arte, requiere poner en juego, simultáneamente, un alto nivel de perfección de su flexibilidad, de su capacidad de desplazamiento y dominio del cuerpo, de su sistema nervioso, respiratorio, muscular y de toda su corporalidad; y simultáneamente y en ese mismo dominio del cuerpo expresa la fuerza de su espíritu, la búsqueda de la belleza y trascendencia que están contenidas en su arte. Este ejemplo nos permite tener una visión más integrada, y comprender que estas dimensiones de la experiencia que representamos en la figura como "polares" no son opuestas sino complementarias, si bien en ocasiones un acentuado énfasis en una de ellas pudiera implicar el descuido o la inhibición del desarrollo de otras dimensiones.

En otro ejemplo iluminante, podemos observar que una entrega generosa a los demás (desarrollo de la sociabilidad) pero que descuide la propia identidad, la seguridad personal, la propia coherencia, el perfeccionamiento de sí como individuo, puede dificultar la misma realización de la sociabilidad; y a la inversa, la individualidad y la generosa sociabilidad se pueden potenciar recíprocamente, cuando un individuo fuertemente volcado a perfeccionarse a sí mismo, por ejemplo a estudiar, a calificarse, a desplegar las propias dimensiones intelectuales, artísticas, científicas, está motivado por el propósito de poder poner todo aquello a disposición de los demás.

O sea, por un lado hay sinergias entre las diferentes dimensiones y necesidades humanas, en cuanto cada una de ellas manda estímulos hacia las otras, las motiva e impulsa a desarrollarse. Uno no puede estar solamen- 
te trabajando en una dirección; por ejemplo, si uno se cansa, si está haciendo demasiado ejercicio físico, necesita descansar; alguien si está demasiado volcado a los demás, en determinado momento necesita una meditación o una lectura o escuchar música o necesita atender y pensar en sí mismo. Hay unas dinámicas que hacen que el proceso de crecimiento vaya conectando estas distintas dimensiones y el sujeto se va desarrollando en cierto modo como en espiral. Pero sin que esto signifique que adquiera una forma redonda, sino que va generando cada uno su personalidad.

\section{b) En las etapas de la vida hay énfasis en distintas dimensiones.}

Otro concepto importante de considerar es que a lo largo de la vida, desde que el individuo o un sujeto social nace y avanza en su crecimiento, tendrá momentos o etapas en las cuales hará énfasis en unas u otras dimensiones de la experiencia. Así en el individuo el primer despliegue es de su cuerpo: tiene que crecer, tiene que existir, tiene que desarrollar sus órganos. Luego tiene que formar su yo antes de volcarse hacia los demás; después desplegará su énfasis en lo social o en lo espiritual. Podríamos incluso decir que la edad infantil está muy centrada en el propio cuerpo, la adolescencia en el yo, la juventud en la sociabilidad, y en la adultez y tercera edad propenden muchas personas a instalarse más en el conocimiento, la creatividad, la trascendencia, el espíritu. Hay estos énfasis en el desenvolvimiento de la vida, que por cierto, no son absolutos; son solamente tendencias, predisposiciones que suelen verificarse en muchas personas. Esto que es válido para el individuo, es válido también para las organizaciones y para las naciones. Por ejemplo, en una pequeña organización (pensemos en una cooperativa) el trabajo en una primera etapa probablemente esté centrado en adquirir una corporeidad, una infraestructura física, en darse una base de sustentación material indispensable para poder, a partir de allí, generar una identidad mayor, una participación en red y vinculación con otros y pensar en proyectos más trascendentes. Las naciones también siguen etapas, siguen procesos; una nación primero enfatiza el desarrollo de su infraestructura, el desarrollo de sus bases materiales, hacer menos precaria su existencia, y también va experimentando etapas: una vez que logra ciertos niveles pone énfasis en otras dimensiones que van complementando su realidad compleja.

Y si es así, podemos suponer que algo similar ocurre también en el sucederse de las civilizaciones, lo cual constituye un concepto interesante de reflexionar en el contexto de esta búsqueda relativa a la creación de una nueva superior civilización.

c) En el despliegue de nuestras dimensiones y necesidades somos atraídos por quienes han alcanzado excelencia, los cuales cumplen un papel fundamental en el desarrollo humano, como individuos y como especie.

Una tercera observación importante se refiere al hecho de que, si bien todos tenemos la potencialidad de alcanzar la excelencia en alguna 
dimensión como efecto de la propia aplicación y energía, hay que tener en cuenta la acción de los otros, de las circunstancias, de las oportunidades y el contexto, que predisponen en ciertas direcciones y que facilitan u obstaculizan el desarrollo. En este sentido, es habitualmente decisiva la relación que pueda establecerse con otras personas, no sólo en las fases infantiles sino también una vez alcanzado un desarrollo maduro.

Un niño que nace en un ambiente de deportistas, donde solo se hable del desarrollo físico, de meter goles, es probable que esté fuertemente atraído a poner énfasis en esa dimensión. Un hijo que nace en un ambiente de lectores de libros, cuyos padres hablan de poesía y novelas y reflexionan sobre lecturas, desarrolla esas necesidades culturales.

En particular, cabe destacar las relaciones con otras personas autónomas, que hayan alcanzado un nivel superior al propio en determinada dirección. Por ejemplo, un gran músico, un gran científico, etc. crecen en el contacto, convivencia e interacción con otro gran músico, científico, etc. Los individuos somos atraídos e impulsados por aquellos que han llegado más arriba o más adelante que nosotros mismos, y esto sucede en cualquier momento de la vida. De aquí la importancia de aprender siempre, y de aproximarse a los grandes hombres, a los maestros de verdad, escucharlos incluso con devoción, porque tienen preciosas perlas que nos regalan gustosos si estamos dispuestos a cogerlas.

Todo esto es muy importante, porque las necesidades las vivimos como energías individuales, pero también las compartimos. Las compartimos y nos retroalimentamos y nos alimentamos mutuamente en el proceso de desarrollarlas. Por eso es esencial la experiencia colectiva, la convivencia, la participación en grupos, redes y organizaciones. Las necesidades las satisfacemos cada uno desplegando sus propias energías y proyectos de realización; pero también las desplegamos en el compartir, en el convivir y en el asociarnos con otros para enfrentar necesidades que nos son comunes. Si uno quiere desarrollar las necesidades espirituales o las necesidades de conocimientos tiene que encontrar personas que quieran lo mismo, porque así van a poder alimentarse en esa búsqueda, en ese trabajo, en esa construcción de los satisfactores de esas necesidades; si uno quiere desplegar su espíritu musical o deportivo, tiene que vincularse a personas que compartan esas dimensiones. Y si nos articulamos en una organización, en una experiencia humana donde se encuentren personas de distintas cualidades, de distantes personalidades, nos enriquecemos también cada uno y a los demás mutuamente, con lo que cada uno haya desplegado más.

Este es otro concepto sumamente importante para superar, en este caso, tanto el individualismo como el colectivismo. Por un lado estamos afirmando las personalidades, la validez de las opciones personales, de los perfiles donde cada uno va desplegando o construyéndose en función de sus propias opciones, y estamos también afirmando y validando la completitud que se adquiere a través de la participación y la vinculación en 
colectivos. Es en este sentido y perspectiva que damos un valor especial a la economía de solidaridad.

\section{d) En el desarrollo y satisfacción de las necesidades se transita desde la dependencia hasta la autonomía.}

El cuarto elemento que queremos destacar para concluir este análisis, es el proceso que -en la satisfacción de las necesidades- conduce al sujeto desde la dependencia hacia la autonomía. Mientras una necesidad está menos desarrollada, más dependerá en su satisfacción de lo externo. Un niño necesita que lo alimenten, que le enseñen, por sí mismo no desarrolla su espiritualidad. Mientras más cerca del punto de origen, más depende de los demás. Podemos expresarlo de otra manera: mientras más la necesidad se expresa como carencia, como vacío (porque todavía es pura potencialidad, todavía no se ha actualizado), más su satisfacción depende de otros sujetos. Cuando va expandiéndose una dimensión, cualquiera de ellas, o sea mientras más amplia sea la satisfacción de la necesidad, más su satisfacción depende de sí mismo, del despliegue de la propia energía, y menos se requieren elementos exteriores que vengan a apagar la necesidad.

Esto nos permite comprender algo muy importante en relación con el desarrollo, porque solamente una vez alcanzado cierto nivel es cuando se hace posible la autonomía. Si uno no ha leído nunca un libro necesita que le enseñen a leer, todo le viene desde fuera, la motivación para leer, el aprendizaje mismo, el incentivo. Pero cuando uno lee y se convierte en un lector, ya nadie tiene que decirle que lea, pues por sí mismo busca libros, necesita leer. Y no solo necesita leer sino que empieza a escribir y se lee así mismo, y ya no espera de otro el cuento, la narración o la elaboración de pensamiento, sino que los crea, inventa las propias historias y las escribe para otros. Son la pobreza, la inseguridad, la carencia de capacidades, la pobreza de relaciones, la ausencia de convicciones, las que hacen necesaria la "riqueza" entendida como abundancia de cosas. De tal manera que en el desarrollo humano, cuando se alcanza cierto grado nos hacemos más autosuficientes, nos hacemos menos necesitados de bienes y servicios exteriores. Si alguien tiene un buen desarrollo personal, amplio, una riqueza de personalidad, es muy probable que necesite menos artículos, pocos productos: no necesita pasarse en el supermercado o en las tiendas o comprando cosas, porque se desarrolla por sí mismo. Le bastan menos bienes y servicios, no porque haya apagado sus necesidades (en un sentido budista), sino porque se desarrolla a sí mismo, despliega su personalidad y pone énfasis en aquellas dimensiones en las cuales es capaz de autogenerar esos proyectos y esos satisfactores de las necesidades. Igualmente, quien ha realizado un gran despliegue de la dimensión espiritual, o un científico que ha avanzado más que todos lo demás, ya no tiene tanto que seguir leyendo a los otros, porque son cosas que él ya sabe: solo le queda seguir el mismo produciendo conocimientos nuevos. 


\section{Bibliografía}

Aristóteles (1986), De Anima, Leviatán, Buenos Aires.

Bergson, H. (1996), Las Dos fuentes de la Moral y de la Religión, Tecnos, Madrid.

Feuerbach, L. (1975), La Esencia del Cristianismo, Ed. Grijalbo, México.

Hume, D. (1999), Tratado de la Naturaleza Humana, Ed. El Viejo Topo, Barcelona.

Leibniz, G. (1986), Discurso de Metafísica, Orbis, Madrid.

içIdem (1981), Nuevo Tratado sobre el Entendimiento Humano; Aguilar, Buenos Aires.

Max-Neef, M., Elizalde, A. y Hopenhayn, M. (1986), Desarrollo a Escala Humana: una opción para el futuro. Número especial de Development Dialogue, Fundación Dag Hammarkjöld, Uppsala.

Marx. K, y Engels, F. (1970), La Ideología Alemana, Ed. Grijalbo, Barcelona.

Razeto, L. (1997), El Misterio del Hombre, Editorial Vivarium, Santiago.

Idem (2004), En Búsqueda del Ser y de la Verdad Perdidos, Editorial U. Bolivariana, Santiago 